\title{
Collegial Support and Community with Trust in Swedish and Danish Dentistry
}

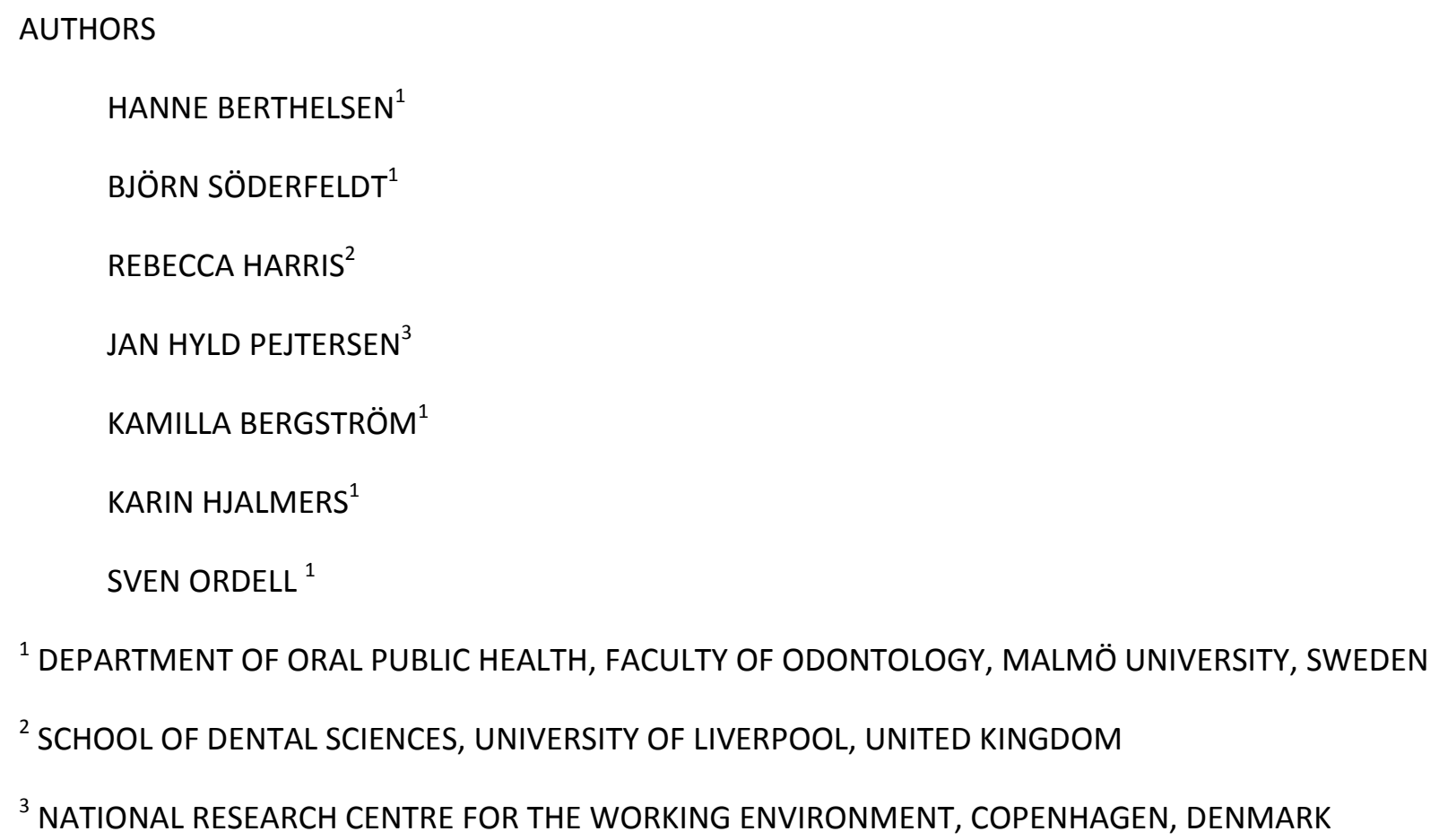




\begin{abstract}
Objectives. The aim of the study was to better understand the associations between work factors and professional support among dentists (Collegial Support) as well as the sense of being part of a work community characterized by trust (Community with Trust).
\end{abstract}

Methods. A questionnaire was sent to 1835 general dental practitioners, randomly selected from the members of dental associations in Sweden and Denmark in 2008. The response rate was $68 \%$. Two models with the outcome variables Collegial Support and being part of a Community with Trust were built using multiple hierarchical linear regression. Demographic background factors, work factors, managerial factors, and factors relating to objectives and to values characterizing climate of the practice were all introduced as blocks into the models.

Results. A different pattern emerged for Collegial Support than for Community with Trust indicating different underlying mechanisms. The main results were: I) Female, married/cohabitant, collegial network outside the practice, common breaks, formalized managerial education of leader, and a climate characterized by professional values were positively associated with Collegial Support, while number of years as a dentist and being managerially responsible were negatively associated. II) Common breaks, decision authority, and a climate characterized by professional values were positively associated with Community with Trust;

Conclusion. A professionally-oriented practice climate and having common breaks at work were strongly associated with both outcome variables. The study underlined the importance of managing dentistry in a way which respects the professional ethos of dentists. 


\section{Background}

Positive work-related states are of importance for overall organizational performance through issues as staff turnover rates and long-term sickness absence [1]. Efficiency in delivery of care is essential for economic sustainability of health care in Europe, where increased expenditures due to population ageing and innovation in health technology is expected [2]. Dentistry is not immune to these challenges [3-4]. Consequently, there is much interest in how to maximise efficiency of dental care delivery, although to date implications for positive work relations have rarely been studied.

In both Sweden and Denmark, dental health care reforms have been implemented during the last few years. The emphasis has been on increasing efficiency through more competition between providers and more team-oriented practice with delegation of tasks. At the same time there has been an increased emphasis on transparency and accountability through e.g. requirements of service declarations, quality assurance and pricelists in waiting rooms. Dental patients more often act as customers in a market with competing providers of dental health care, and thereby the changes are commensurate with the ideology of New Public Management [5]. Larger organizational units are currently favoured in both Sweden and Denmark [6,7]. In combination with increased delegation of tasks this necessitates a greater need for coordination of activities to ensure continuity in patient care. Larger organizations tend to operate via written guidelines, rather than the traditional trust-based relationships and modes of communication characteristic for traditional professional work units [8].

Dentistry is an instance of a Human Service Organization (HSO), where human relationships, to patients and to colleagues, are essential according to the theories of 
Hasenfeld $[9,10]$. Indeed such relationships are an important job resource for dentists and may even buffer highly demanding work environments [11,12]. Relationships between members of the dental team may therefore be a means to resolve some of the practical and emotional issues which arise from work with patients $[13,14]$. Moreover, such relationships are also reported to be one of the job rewards instrumental in finding such work satisfying $[11,15]$.

The structures and the management of an organization are fundamental to its culture which can be defined as the shared basic assumptions, values, and artefacts [p. 14 in [16]], and for the climate in dental practices understood as employees' perception of values and goals characterizing their work unit [17]. Trust, collegiality, and discretion in work are regarded as traditional core values for professionals in general [8]. With regard to dentists also such values in relation to their work have been recognized [15,18-22]. It has been argued that in the health care sector as a whole the current managerial trends result in more emphasis on organizational professionalism rather than on occupational professionalism [23,24]. Organizational professionalism can be seen as a discourse of control involving changes in authority, responsibility, and trust [23]. Externalised forms of regulation challenge professional ethics [23] and the traditional role of health care professionals comes under pressure [23,24].

Gorter has argued that it is rather the fit between the dentist and practice characteristics, than the practice characteristics per se, that influence job resources and wellbeing at work [25]. However, when great differences are documented for dentists working in different organizational settings it seems relevant to study which factors, besides personal and direct work-related attributes, that may contribute to explanations for such discrepancies. Bejerot has concluded that it is important to include management doctrines in analyses [21]. Her research concluded, that dentists working in the public sector had larger discrepancies 
between ideal and reality in their work than their colleagues working in the private sector [21]. In a similar way, Harris has shown differences in job satisfaction between dentists working in the private and in the public sector in the UK and pointed out the importance of including organizational and cultural issues in the measurement of job satisfaction $[19,26]$. In Sweden and Denmark differences in level of support from colleagues in relation to work with patients (Collegial Support) and differences in the perception of being part of a team characterized by trust and humour (Community with Trust) have previously been documented among dentists working in different organizational settings [27]. For example, dentists from the public sector perceived more Collegial Support than dentists from the private sector. Private practitioners from Sweden reported a higher average for Community with Trust than did their colleagues from public practices, while a corresponding difference was not documented in Denmark [27]. In other words, the dental practice may be influenced by the organizational translation of the context for work. A number of hypotheses can be stated concerning the impact of current contextual changes for dentistry, and the aim of this study is to test the following hypotheses.

1. Differences in social support have been revealed between dentists working in singlehanded practices and in group practices [13]. Typically, in larger practices, different staff groups are more likely to be present, and thereby delegation of tasks to dental hygienists and nurses is more probable. This may strengthen the potential to achieve a social community through collaboration as teams as presumed by the Danish National Board of Health [6]. The size of practice, measured as number of dentists, can therefore be expected to be positively associated with Collegial Support and Community with Trust.

2. Structural conditions can be expected to influence collaboration among colleagues in daily work. When all personnel meet for common breaks at the practice, it provides 
opportunities for social exchange and thereby for formation of positive relationships and informal conflict prevention. Consequently, frequency of common breaks can be expected to be positively associated with Collegial Support and Community with Trust.

3. Factors concerning management are also believed to be important for a positive atmosphere at work $[21,22,28]$. The importance of social relations and methods to affect these are central themes in modern management theories. A formalised managerial education of the daily leader (understood as the local manager or the head of practice) may for that reason be positively associated with Collegial Support and Community with Trust.

4. Dentists find it important to have influence over whom they collaborate with [15]. Dentists with influence may utilise this to find people with whom they like to work. Moreover, the more influence, the easier it is to comply with the demands of the work, resulting in less stress and stress-released conflicts [29]. Perceived influence may thus covary with Collegial Support and Community with Trust.

5. Professionalism is an important perspective to include when studying factors contributing to satisfaction with work as a dentist [26]. Professions are known to apply internal justice and order, and to establish norms through their social relations concerning work [30]. A practice climate characterized by values expressed by the profession [15] can therefore be expected to be positively associated with Collegial Support and Community with Trust.

6. A typical characteristic of Human Service Organizations is that it is difficult to find relevant measures of efficiency because of the nature of the work [9]. As a result, there may be a tendency to measure productivity rather than efficiency with a risk of fostering a more competitive than supportive atmosphere $[7,31]$. Thus we hypothesize that a 
productivity-orientated climate can be expected to be negatively associated with Collegial Support and Community with Trust.

\section{Material and methods}

\section{Study base}

1835 general dental practitioners from private or public practices in Sweden and Denmark received a mailed questionnaire comprising 39 questions with corollary question batteries. The questionnaire was designed to cover positive aspects of dentistry and the psychosocial work environment in general [27,32]. The sample was randomly selected from active general dental practitioners registered in the dental associations in Denmark and Sweden. Data was collected between October 2008 and January 2009. The response rate was $68 \%$ after two reminders. For private practitioners coming from Denmark the response rate was lower than for the other groups. Therefore, a non-response analysis based on telephone interviews was performed for this group. A more detailed description of the study base has previously been published [27,32].

The study was approved by The Regional Ethical Review Board in Lund, Sweden (H15 501/2008). In Denmark no such permission was required.

\section{Dependent variables}

Regression models were built with scales for Collegial Support and Community with Trust respectively as dependent variables. Details concerning development, validation and characteristics of the scales have recently been published [13,27].The scale for Collegial Support was based on five questions about the extent to which difficult treatments, problems concerning dissatisfied patients, and well-being are discussed with colleagues, as well as having opportunity for practical assistance from a colleague if needed, and having a colleague with whom a potential complaint proceeding could be discussed. The scale for Community 
with Trust included nine questions concerning the perception of being part of a work-related community with a positive atmosphere characterized by collaboration, mutual trust, humour, and a positive atmosphere. All items had 5 response alternatives measured on a 5 step Likert scale. An additive index with a range 0-100 was established for both scales giving each of the items the same weight. Both scales were approximately normally distributed but with a skew distribution toward high scores for the total sample.

\section{Independent variables}

The independent variables were subdivided into four groups covering personal background factors, structural work factors, managerial factors, and practice climate factors.

Personal background factors were gender, number of years since graduation from dentist school, and marital status (living as a single person or married/cohabitant).

Structural work factors were work country (Sweden or Denmark), work sector (public or private), collegial network outside the practice (measured as opportunities for meeting other dentists on courses, conferences, association meetings or similar as well as in leisure time and the frequency thereof during the last year with response alternatives: every week, every month, seldom, never/almost never. An additive index with a range 0-100 was established giving each of the items the same weight), number of weekly work hours with direct patient contact (measured as a direct question), size of practice (measured as number of dentists at the practice where the normal work takes place), and frequency of having common breaks at work (response options: never/almost never, seldom, occasionally, often, always/almost always).

Managerial factors included whether the dentist had decision authority (yes or no), managerial responsibility (yes or no), and if the daily leader had formalized managerial education (yes or no/do not know). Decision authority was based on eight items about the 
respondents' influence on the following circumstances: The brand of filling material used at the practice, choice of dental technician, the assistant nurse, employment of new personnel, scheduling appointments, scheduling acute patients, choice of own courses, goal formulations of the practice. The response options were: none, some, decide myself. The variable was constructed as dichotomous based on having one or more circumstance with non influence ('no') versus having some or full influence over all circumstances ('yes').

Practice climate was based on previous research [15,19-22] measured by asking respondents to grade how they thought different factors characterized the goals and values of the practice. The response options were: to a very low degree, to a low degree, to some degree, to a high degree, to a very high degree. Based on theoretical considerations and supported by a Principal Component Analysis (PCA) with Varimax rotation (Table I), the variables were combined into two additive indexes: professional climate (range 0-100, Cronbach's alpha value 0.87 , based on the items: initiative, technical quality, engagement, flexibility, service-oriented, creativity, and professional development) and productivity climate (range 0-100, Cronbach's alpha value 0.70, based on the items: productivity, efficiency, income-oriented). The Kaiser Criterion and inspection of scree plots were used for determination of the number of factors. The analysis was run for subsamples according to gender, nationality and work sector in order to assess consistency across the data and found to be stable.

\section{Statistical methods}

Differences in characteristics of the study population in relation to organizational affiliation were analysed using Pearson's Chi-Square test, 1-way ANOVA and Kruskal Wallis' test with a significance level at 0.05 . 
Multiple hierarchical linear regression analyses were performed with the scales of Collegial Support and of Community with Trust as dependent variables. The independent variables were included in four steps. In each step, a block of variables (personal background factors, work factors, managerial factors and practice climate factors) was included in the model. The order of blocks was based on theoretical considerations implying that basic and structural blocks should be included before assumed culturally consequential blocks, thus following the logic of a presumed causal order [33].

Inter-correlations between independent variables and variance inflation factors (VIF) were checked for both models in the different steps. Durbin Watson statistics were calculated, residual plots and Cook's distances were inspected for the final models [34].

Preliminary analyses were run separately for four groups based on work country and sector to exclude the risk of potential interaction effects. The overall pattern was similar across organizational affiliation. Therefore, it was decided to include the variables work country and work sector in the second block of the regression analyses. The final analyses were also checked for interaction effects between other independent variables (gender, sector, managerial responsibility, practice climate).

All analyses were performed using SPSS version 16.0. 


\section{Results}

\section{Study population}

Characteristics of the study population are presented in Table II. Except for the variable living alone significant differences were found among the four subgroups based on organizational affiliation. Dentists from the Danish public sector worked on average fewer hours per week with patients than all the other groups did, and dentists from the Swedish public sector worked fewer hours than dentists coming from private practices. The Swedish public practitioners reported on average lower network activities than the other groups did. No difference was found for professional climate between public and private practitioners in Denmark, while in Sweden public dentists reported lower scores and private practitioners higher scores than all other groups. Danish public dentists reported lower productivityoriented climate than all other groups. Respondents coming from private practices had on average worked more years since graduation than their colleagues coming from public practices.

\section{The regression model}

The regression models are presented in Table III and Table IV. No serious signs of multicollinearity were indicated as the highest correlation between independent variables was between the dichotomous variables having managerial responsibility and decision authority [0.67]. All other correlations were lower and no VIF was found higher than 2.0. Cook's distances were inspected for detection of outliers, and no extreme values were found. Residual plots were inspected and supported the assumption of a homoscedastic error term for the final two models. Durbin Watson statistics were calculated and found to be satisfactory, indicating no signs of positive serial correlation. All models were significant at the 0.001 level. 


\section{Collegial Support}

The regression model with Collegial Support as the dependent variable is presented in Table III. The block of personal demographic variables remained significantly, steadily associated with Collegial Support through all four models. Female dentists and married dentists reported more Collegial Support than their counterparts, keeping all other variables constant. Further, the more years since graduation, the less Collegial Support was stated. Among work factors, seeing dentists outside the practice, frequency of common breaks at work, and number of dentists at the practice where the work takes place, were positively associated with Collegial Support. Dentists with a managerial responsibility reported less support than those without, while a formalized managerial education of the daily leader was associated with more Collegial Support. Cultural organizational factors drew their associations especially from decision authority, but also from frequency of common breaks and formalized managerial education of leader. In a similar way as in the model for Community with Trust, working in a practice with a professional climate was positively correlated with Collegial Support, and the association with productivity climate negatively, but insignificant $(\mathrm{p}=0.06)$. All in all, the final model for Collegial Support explained 24 percent of the total variance and the block of work factors contributed most to the explanation, albeit several independent variables contributed significantly to the explained variation.

\section{Community with Trust}

Differences in the level for Community with Trust based on work country and sector as well as differences due to personal demographic factors, disappeared, when controlling for managerial and cultural organizational factors (Table IV, model D). When introducing the block of practice climate factors to the preceding model (model C to model D), the significant associations with work sector, collegial network outside the practice and formalized managerial education of leader disappeared and the associations with frequency of common 
breaks and decision authority became weaker. The strongest association was seen for working in an organization with goals and values in line with core professional values. A weak negative association with productivity was found, albeit insignificant $(\mathrm{P}=0.06)$. To sum up, having decision authority at work, more common breaks, and the more the dentists perceived the values and goals for the practice as reflecting professional values, the higher degree of Community with Trust was reported, when controlling for all other factors. Introducing practice climate factors in the model gave a substantial additional explanation of the variance. The final model explained approximately half of the variance in data (adjusted $\mathrm{R}^{2}=0.49$ ). 


\section{Discussion}

An overview of results in relation to the hypotheses is provided in Table V and will be discussed in the following section.

\section{Hypothesis 1.}

As expected, the number of dentists in a practice was positively associated with Collegial

Support. In contrast to the hypothesis, no association was found in relation to Community with Trust. The results concerning Collegial Support are in line with previous findings [13].

Naturally, Collegial Support is primarily based on interactions among dentists [22]. In a similar way, social interactions and communicative support for problem solving are in a hospital emergency department also shown mainly to be within each professional group [35]. Community with Trust differs from Collegial Support as it involves a broader relational sphere, including auxiliaries as well as management. When more professional groups are gathered there are potentially more conflict areas due to demarcations and conflicting interests. Conflict management is important for a team's interdependence and social closeness within the context of dentistry [28]. It is often taken for granted that positive relations are an integral part of advantages of scaling. However, all though Collegial Support was associated with larger practice units, apparently Community with Trust does not come by itself, but has to be worked for. A way forward could be through a proactive team-oriented leadership [28].

\section{Hypothesis 2.}

Frequency of common breaks at the practice was as expected positively associated with Community with Trust as well as with Collegial Support. The finding corroborates that structural conditions are a framework for the shaping of professional relationships. In practices with more people present and common breaks in daily work, the colleagues are near by, which may nurture opportunities for social exchange and support. Among teachers, which constitute another human service group, such interspaces have also been found to mitigate 
stress through improved support [36]. Even though breaks are often used for catching up on the schedule, other functions are also important [31]. Breaks are a breathing space with opportunities for talking about everyday life and concerns on equal terms, and thereby build confidence, respect and mutual understanding, which ultimately may contribute to the creation of social capital. From a public health perspective work breaks are believed to have a considerable health promotion potential [37]. Another important feature of dentistry today is the desire for lifelong learning and reflective practice [38]. Common work breaks and regular meetings may constitute a frame for exchange of viewpoints, tips and new knowledge as well as time for common reflection [28]. Thereby, breaks can help in coping with difficulties and ethical problems at work, as well as contributing to common learning processes and development of a work-related community.

\section{Hypothesis 3.}

The associations for managerial factors became weaker when practice climate factors were included in the models. Formalized managerial education of the leader remained significant in the final model for Collegial Support, but not for Community with Trust. Maybe the explanation might be found in the fact, that in both countries the majority of leaders within dentistry are dentists, whereof some have an additional managerial education. This gives a situation with two different roles and identities within the same person: the dentist as the professional and the dentist as the leader. Leadership for professionals is typically legitimized through being primus inter pares (first among equals), while the role is different in relation to other staff groups [30].The result could indicate that the primary identity, even when having managerial responsibility, is still grounded in the profession as dentist. A supporting fact for this interpretation may be that clinic heads - employer representatives - are still usually members of the same professional association as their subordinate colleagues. 


\section{Hypothesis 4.}

Decision authority remained significantly positively associated with Community with Trust, but not with Collegial Support when practice climate factors were included in the models. The result concerning Community with Trust corroborates previous findings of participative decision making as a contributor to the sense of team identity [28]. Having knowledge of what is going on and having influence over daily work is known to reduce stress [29]. Further, openness may prevent rumours and insecurity and thereby also support the creation of trust in the work unit. As to Collegial Support, it indicates that dentists have their own culture with relations independent of the degree of control over their work situation. This is corroborated by previous somewhat contradictory results concerning Swedish publicly employed dentists. Rolander found high social support but low job control [39], while Hjalmers found both a low degree of social support and low job control among unpromoted female dentists [20].

\section{Hypothesis 5.}

Dentists working in a professionally oriented climate were more likely to report considerably higher levels of both Collegial Support and Community with Trust. Dentistry is characterized as a classical profession [22,40-42]. From this perspective, the result is not surprising as professionals such as dentists establish, maintain, and develop their norms also through their social relations. Creativity, professional development, and influence are regarded as essential for delivering high quality health care and are therefore also fundamental for the perception of having a good work $[15,20]$. Thereby, the results indicate that it is more an issue if the climate supports the ideals of the profession than it is question of managerial factors; - or rather, that managerial factors can be effective only through the professional ethos. This conclusion is in accordance with previous research on dentists, emphasizing the importance of correspondence between personal values and organizational objectives [21,22]. 


\section{Hypothesis 6.}

Even though there was a tendency that dentists working in organizations with a pronounced productivity-oriented climate reported lower Collegial Support and Community with Trust, the associations were insignificant in the final models $(\mathrm{p}=0.06)$. Naturally, productivity is an important part of every job. The relation between productivity and the concern for staff has been theorized about for years, e.g. already in 1964 in the Managerial Grid [43]. The ideal leadership according to the Managerial Grid is to have high concern for productivity as well as for the people, through emphasis on teamwork and commitment. The present results, interpreted through this model, indicate that the management of dentistry today does not correspond with this ideal leadership. Based on a review of associations between well-being and productivity, Kristensen has concluded that a positive work environment with social capital built on justice, community and trust can be a core contributor to higher productivity as well as to better quality [44]. All in all, there seems to be an unexploited opportunity for improvements within dentistry, if outcome measures to a greater extent can be formulated in correspondence with such visions of quality in work combined with productivity. This would be a way to join the norms of the health professional and of the organization and thereby improve work environment.

\section{Deeper implications of the results}

A different pattern was documented for Collegial Support than for Community with Trust in a number of ways for the final models. First of all, the associations for all background factors in relation to Community with Trust became insignificant when the other factors were included in the model, while all the corresponding associations remained significant in relation to Collegial Support. This finding, combined with the fact that the model explained about half of the variance for Collegial Support in relation to Community with Trust, indicates that different predictors are at play. For Collegial Support, a substantial difference was seen as female 
dentists perceived much higher Collegial Support than male respondents. A corresponding difference has previously been documented and discussed in relation to emotional support among general dental practitioners from Danish private practices [13].

For demographic background and work factors, similar tendencies as in the present results have been shown in relation to perceived support among Danish general practitioners from private practices [13]. However, frequency of common breaks was a new item, which as expected was significantly positively correlated with Collegial Support.

Dentists with a managerial responsibility and dentists with long experience within the profession were associated with declining Collegial Support in the present study. The same tendency has been seen for dentists coming from Danish private practices and for support from close colleagues among European nurses $[13,45]$. This is interpretable from the assumption that perceived support to a certain extent reflects the actual needs for this. The way Collegial Support was measured in the present study emphasized the dentists as human service workers where patient-related work is the core. The social interaction with colleagues changes over time as the professional becomes more experienced [15]. Among younger dentists the need for advice and recommendation is more pronounced, while the role of the more experienced colleagues ideally is being a mentor for the younger colleagues [15]. The professional identification process is obviously in its beginning for younger dentists and more established for the older ones. A similar reasoning can explain that leaders perceived less Collegial Support compared to dentists without managerial responsibility. The result makes sense as leaders have a duality in their role implying that their need for support may be of a managerial kind rather than related to clinical work.

However, this latter result differs from previous findings on Danish private practitioners in 2002 [13]. It is hard to say why it differs from the previous findings. Among 
the reasons could be that the present sample is different as it also includes leaders coming from public practices and the non-response was higher among private practitioners especially from Denmark. The present sample was more diversified and the average size of practices was larger. In small organizational units the role of the leader is more like an equal among equals with shorter hierarchical distance than in larger units. However, better leadership is reported in the Danish workforce as a whole [46]. Therefore, another possible explanation of the inconsistency with previous findings could be that the role of the leader has changed as a result of more emphasis on this part of the job. For example, courses in conflict solving, communication, management, and business economy have become more the core of the course programme offered to private practitioners in Denmark during the same period.

A full understanding of the results necessitates relating them to organization. The New Public Management oriented reforms are implemented differently in Sweden and Denmark [5]. Freidson argues that three different governing logics exist; bureaucratic, market, and professional governing principles. In the bureaucratic model the managers are in power, while in the market one, consumers have decisional influence. In the third logic, professionals are especially influential [30]. If we apply this theory to the four organizational forms under study, private dentistry is based on a balance between the forces from the market and from the profession. Danish public dentistry is primarily based on a balance between bureaucracy and profession, since consumerism and market orientation have not been widely implemented. On the other hand, public dentistry in Sweden is characterized by a balance between especially bureaucratic and market forces, leaving the dentists with little influential power, maybe even amounting to a mismatch between the original ethos of the organization and reality [20]. The main results of this study point to that variation in Community with Trust and Collegial Support to a great extent can be explained by differences in organizational priority of 
facilitating a professional developing climate. Support from colleagues and a work-related community can be perceived as part of a socializing process where norms are created and evidence is translated to the practice and thereby constitute a development of the fundamentals of dentistry.

Finally, linking back to the issue of organizational efficiency, the results can be put into perspective by the results of Hakanen et al. from 2008 illustrating positive gain spirals at work for a cohort of dentists [47]. One example of such a gain spiral shows that job resources predict dentists work engagement, which in itself has a positive impact on future job resources as well as on initiatives at both individual and work unit level [47]. Thereby, individual resources can be linked to work unit outcomes, giving a win-win situation for work environment as well as organizational performance. In a similar way important job resources such as Collegial Support and Community with Trust may also be expected to contribute to long term organizational efficiency through such gain spirals. In addition, the findings of the present study suggest, that also a professionally-oriented climate and work breaks may be perceived as job resources for dentists in addition to previously formulated job resources $[11,12]$.

\section{Discussion of material and methods}

A strength of the study is that we used a random sample. In addition, dentists coming from different organizational forms and countries were included which gives a wider scope for possible generalizations as the results were stabile across organizational affiliation. Another strength is that the scales under study are validated for use on the same sample population.

The current problem of increasing difficulties in obtaining a high response rate, and the fact that a high non-response rate enlarges the risk of bias are well known [48,49]. However, the response rate was high for all groups except for the dentists coming from private practices 
in Denmark, for whom it was moderate. The previously published non-response analysis comparing respondents and non-respondents among dentists from Danish private practices showed no significant differences on core variables as job satisfaction and self-rated health, even though non-respondents were more likely to be males with managerial responsibility [32].

About 50 percent of the actively practicing general dental practitioners are females, in Sweden as well as Denmark [50]. The gender distribution among respondents from Sweden conforms to the total population, while there seems to be a substantial overrepresentation of women among the Danish participants. Besides the lower response rate among male dentists from Danish private practices, the skewed gender distribution can also be explained by a higher response rate in the public compared with the private sector. In the public sector, the percentage of female dentists is higher than in the private sector.

The final models were run separately for groups based on gender, number of dentists and having managerial responsibility in order to exclude the risk of different patterns in these subgroups. No great differences were found; hence it was decided to include these variables in the models. As the overall pattern for the regression models was similar across organizational affiliation, and as gender and position were also included in the models, the response bias may not be regarded as biasing the overall conclusions regarding the associations.

A limitation of the present study is the cross sectional design, as causation cannot be inferred from the results. A further limitation may be that all variables were based on selfreported data, which may have introduced a risk of common methods bias [51]. Especially, associations between Community with Trust and practice climate factors are at risk, as these variables represent socially desirable outcomes and are of attitudinal kind. Some precautions were taken as recommended by Podsakoff [51]: Psychological separation was considered, as 
hypotheses were not given in the introduction to the questionnaire. The questions were also formulated minimizing item ambiguity, and well spread in the questionnaire. Confidentiality was assured to reduce social acceptability bias. Finally, all items included in the two dependent variables and practice climate variables were included in a PCA, resulting in a clear four-factor solution (not presented), indicating that common methods bias probably is a minor problem [51].

A further limitation is the use of ordinary least squares regression only. First, it would have been desirable to do a multilevel analysis of the organizational factors, which could not be done due to the sample design. No other sampling frame was available than the one used, making it unfeasible to sample at practice level. Second, a logical next step would be to use structural equation modelling to assess indirect effects including the relations between the two dependent variables and also with job satisfaction. That will, however, be done in future research.

\section{Conclusions}

The differences in Collegial Support and Community with Trust for dentists working in different countries and sectors could be explained when other factors were introduced in the regression models. This is an argument for the universal character of the factors studied here. There were, however, indications for different mechanisms behind Collegial Support and Community with Trust. The main results point to that variation in Community with Trust and Collegial Support to a great extent can be understood through disparities in organizational priority of facilitating a professional developing climate. Support from colleagues and a workrelated community can be perceived as part of a socializing process where norms are created and evidence is translated to the practice and thereby constitute a development of the fundamentals of dentistry. The study underlines the importance of managing dentistry in a 
way which corresponds with the professional ethos of dentists in upcoming health care reforms.

\section{Acknowledgements}

The authors wish to acknowledge the Swedish Council for Working Life and Social Research and the Danish Dental Association for financial support of the study. We also want to acknowledge Acta Odontologica Scandinavica for publishing the present article, which in a preliminary version has been published in the doctoral thesis "Work-related support, community and trust -dentistry in Sweden and Denmark" defended by the first author (Hanne Berthelsen) at Malmö University the $12^{\text {th }}$ of November 2010. 


\section{References}

[1] Clausen T. Psychosocial work characteristics, positive work-related states, and labour market outcomes. A study of the antecedents and consequences of affective organizational commitment and experience of meaning at work. Copenhagen: Danish Research School of Psychology, 2010 (Dissertation).

[2] Thomson S, Foubister T, Mossialos E. Financing health care in the European Union: Challenges and policy responses. European Observatory on Health Systems and Policies. Observatory Studies Series N ${ }^{0} 17$. The European Union, World Health Organization, 2009.

[3] Harford J. Population ageing and dental care. Community Dent Oral Epidemiol 2009; 37:97-103.

[4] Gallagher JE, Kleinman ER, Harper PR. Modelling workforce skill-mix: how can dental professionals meet the needs and demands of older people in England? Br Dent J 2010; 208(3):E6-E7.

[5] Green-Pedersen C. New Public Management reforms of the Danish and Swedish Welfare States: The Role of Different Social Democratic Responses. Governance 2002; 15:271-94.

[6] The Danish National Board of Health. Tandplejens struktur og organisation [Structure and organization of dentistry]. 2004. Copenhagen, The Danish National Board of Health.

[7] Ordell S, Söderfeldt B. Management structures and beliefs in a professional organisation. An example from Swedish Public Health Services. Swed Dent J 2010; $34: 167-76$.

[8] Evetts J. Introduction: Trust and Professionalism: Challenges and Occupational Changes. Curr Sociol 2006; 54:515-31.

[9] Hasenfeld Y. The Attributes of Human Service Organizations. In: Hasenfeld Y, editor. Human Services as Complex Organizations. Los Angeles: Sage, Inc., 2009:9-32.

[10] Guy ME, Newman MA, Mastracci SH, Maynard-Moody S. Emotional Labor in the Human Service Organization. In: Hasenfeld Y, editor. Human Services as Complex Organizations. Los Angeles: Sage, Inc., 2009: 291-309.

[11] Hakanen JJ, Bakker AB, Demerouti E. How dentists cope with their job demands and stay engaged: the moderating role of job resources. Eur J Oral Sci 2005; 113:479-87. 
[12] Gorter R, te Brake J, Eijkman M, Hoogstraten J. Job resources in Dutch dental practice. Int Dent J 2006; 56:22-8.

[13] Berthelsen H, Hjalmers K, Söderfeldt B. Perceived social support in relation to work among Danish general dental practitioners in private practices. Eur J Oral Sci 2008; 116:157-63.

[14] Hjalmers K, Söderfeldt B, Axtelius B, Kronström M. Network participation for unpromoted female dentists in relation to psychosocial support. Acta Odontol Scand 2004; 62:158-62.

[15] Berthelsen H, Hjalmers K, Pejtersen JH, Söderfeldt B. Good work for dentists -a qualitative analysis. Community Dent Oral Epidemiol 2010; 38:159-70.

[16] Schein E. Organizational Culture and Leadership. London: Jossey - Bass, 1985.

[17] Hemmelgarn AL, Glisson C, James LR. Organizational Culture and Climate: Implications for Services and Intervention Research. In: Hasenfeld Y, editor. Human Services as Complex Organizations. Los Angeles: Sage Publications, Inc., 2009:229_ 50.

[18] Harris RV, Dancer JM, Montasem A. The impact of changes in incentives and governance on the motivation of dental practitioners. Int J Health Plann Mgmt 2010; 25:1-20.

[19] Harris RV, Ashcroft A, Burnside G, Dancer JM, Smith D, Grieveson B. Facets of job satisfaction of dental practitioners working in different organisational settings in England. Br Dent J 2008; 204(1):E1-E7.

[20] Hjalmers K. Good work for dentists - ideal and reality for female unpromoted general practice dentists in a region of Sweden. Swed Dent J Suppl 2006; (182):10-136. (Dissertation).

[21] Bejerot E. Dentistry in Sweden - Healthy work or ruthless efficiency? Lund: National Institute for working Life, Lund University. Arbete och hälsa. Vetenskaplig skriftserie, 1998:14 (Dissertation).

[22] Franzén C. Att vara en tandläkare i folktandvården. [To be a dentist in the public dental service] Malmö: Faculty of Odontology, Malmö University, 2009 (Dissertation).

[23] Evetts J. New Professionalism and New Public Management: Changes, Continuities and Consequences. Comparative Sociology 2009; 8:247-66.

[24] Sehested K. How New Public Management Reforms Challenge the Roles of Professionals. Int J Pub Adm 2002; 25:1513-37. 
[25] Gorter RC, Te Brake HJ, Hoogstraten J, Eijkman MA. Positive engagement and job resources in dental practice. Community Dent Oral Epidemiol 2008; 36:47-54.

[26] Harris RV, Ashcroft A, Burnside G, Dancer JM, Smith D, Grieveson B. Measurement of attitudes of U.K. dental practitioners to core job constructs. Community Dent Health 2009; 26:43-51.

[27] Berthelsen H, Pejtersen JH, Söderfeldt B. Measurement of social support, community and trust in dentistry. (In press).

[28] Chilcutt AS. Exploring leadership and team communication within the organizational environment of a dental practice. J Am Dent Assoc 2009; 140:1252-8.

[29] Karasek R. Job demands, job decision latitude, and mental strain: implications for job redesign. Admin Sci Q 1979; 24:285-308.

[30] Freidson E. Professionalism. The Third Logic. Cambridge: Polity Press, 2001.

[31] Bejerot E, Theorell T. Employer control and the work environment: a study of the Swedish Public Dental Service. Int J Health Serv 1992; 22:669-88.

[32] Bergström K, Söderfeldt B, Berthelsen H, Hjalmers K, Ordell S. Overall job satisfaction among dentists in Sweden and Denmark - a comparative study, measuring positive aspects of work. Acta Odontol Scand 2010; 68:344-53.

[33] Davis AD. The Logic of Causal Order. London: sage Publications Ltd, 1985.

[34] Studenmund AH. Using Econometrics: A Practical Guide. Pearson International Edition. 5th ed. London: Pearson Addison Weasley, 2006.

[35] Creswick N, Westbrook JI, Braithwaite J. Understanding communication networks in the emergency department. BMC Health Serv Res 2009; 9:247.

[36] Nordänger UK. Lärares raster. Innehåll i mellanrum.[Teachers' breaks] Lund: Lund University, 2002 (Dissertation).

[37] Taylor WC. Transforming work breaks to promote health. Am J Prev Med 2005; 29:461-5.

[38] Simpson K, Freeman R. Reflective practice and experiential learning: tools for continuing professional development. Dent Update 2004; 31:281-4.

[39] Rolander B, Stenström U, Jonker D. Relationships between psychosocial work environmental factors, personality, physical work demands and workload in a group of Swedish dentists. Swed Dent J 2008; 32:197-203. 
[40] Gallagher JE, Clarke W, Eaton KA, Wilson NH. Dentistry - a professional contained career in healthcare. A qualitative study of Vocational Dental Practitioners' professional expectations. BMC Oral Health 2007; 7:16.

[41] Ordell S, Unell L, Söderfeldt B. An analysis of present dental professions in Sweden. Swed Dent J 2006; 30:155-64.

[42] Welie JV. Is dentistry a profession? Part 3. Future challenges. J Can Dent Assoc 2004; 70:675-8.

[43] Blake RR, Mouton JS. The managerial grid. Houston, Texas: Gulf Publishing Co, 1964.

[44] Kristensen TS. Trivsel og produktivitet - to sider af samme sag. En litteraturgennemgang. [well-being and productivity -two sides of a coin. A literature review] 2009. Copenhagen, HK/ Danmark.

[45] van der Heijden BI, Kummerling A, van Dam K, van der SE, Estryn-Behar M, Hasselhorn HM. The impact of social support upon intention to leave among female nurses in Europe: Secondary analysis of data from the NEXT survey. Int J Nurs Stud 2009; 47:434-45.

[46] Pejtersen JH, Kristensen TS. The development of the psychosocial work environment in Denmark from 1997 to 2005. Scand J Work Environ Health 2009; 35:284-93.

[47] Hakanen JJ, Perhoniemi R, Toppinen-Tanner S. Positive gain spirals at work: From job resources to work engagement, personal initiative and work-unit innovativeness. J Vocat Behav 2008; 73:78-91.

[48] Cook JV, Dickinson HO, Eccles MP. Response rates in postal surveys of healthcare professionals between 1996 and 2005: an observational study. BMC Health Serv Res 2009; 9:160.

[49] Edwards PJ, Roberts I, Clarke MJ, Diguiseppi C, Wentz R, Kwan I et al. Methods to increase response to postal and electronic questionnaires. Cochrane Database Syst Rev 2009; (3):MR000008.

[50] Kravitz AS, Treasure ET. EU Manual of Dental Practice: version 4 (2008]. 2008. Brussels, The Council of European Dentists.

[51] Podsakoff PM, MacKenzie SB, Lee JY, Podsakoff NP. Common Method Biases in Behavioral Research: A Critical Review of the Literature and Recommended Remedies. J Appl Psych 2003; 88:879-903. 


\section{Tables}

Table I. PCA with varimax-rotated factor loadings for questions on organizational values. Major loadings marked in bold face.

\begin{tabular}{|lccc|}
\hline Item & $\begin{array}{l}\text { Factor 1 } \\
\text { (Professional } \\
\text { climate) }\end{array}$ & $\begin{array}{l}\text { Factor } \mathbf{2} \\
\text { (Productivity } \\
\text { climate) }\end{array}$ & Communality \\
Creativity & $\mathbf{0 . 8 1}$ & 0.11 & 0.66 \\
Engagement & $\mathbf{0 . 7 8}$ & 0.12 & 0.63 \\
Professional & $\mathbf{0 . 7 8}$ & 0.16 & 0.63 \\
Initiative & $\mathbf{0 . 7 4}$ & 0.22 & 0.59 \\
Service oriented & $\mathbf{0 . 7 4}$ & 0.09 & 0.55 \\
Flexibility & $\mathbf{0 . 7 2}$ & 0.12 & 0.54 \\
Technical quality & $\mathbf{0 . 5 9}$ & 0.26 & 0.41 \\
Productivity & 0.31 & $\mathbf{0 . 8 3}$ & 0.79 \\
Efficiency & 0.42 & $\mathbf{0 . 7 7}$ & 0.77 \\
Income oriented & -0.08 & $\mathbf{0 . 7 3}$ & 0.54 \\
\hline Eigenvalue & 4.71 & 1.39 & \\
Variance explained (\%) & 41.0 & 20.1 & \\
\hline
\end{tabular}


Table II. Characteristics of the study population based on organizational affiliation.

\begin{tabular}{|c|c|c|c|c|c|}
\hline & \multirow{2}{*}{ Groups } & \multicolumn{2}{|c|}{ Sweden } & \multicolumn{2}{|c|}{ Denmark } \\
\hline & & private & public & private & public \\
\hline \multirow{7}{*}{ 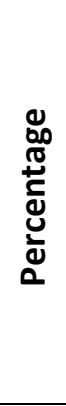 } & Female respondents & $32.9 \%$ & $70.4 \%$ & $65.1 \%$ & $87.4 \%$ \\
\hline & Living alone & $9.0 \%$ & $13.8 \%$ & $12.1 \%$ & $15.1 \%$ \\
\hline & Solo practice & $38.4 \%$ & $2.7 \%$ & $15.5 \%$ & $20.0 \%$ \\
\hline & Always/almost always common breaks & $59.7 \%$ & $71.0 \%$ & $48.2 \%$ & $73.2 \%$ \\
\hline & Without managerial responsibility & $9.3 \%$ & $85.2 \%$ & $23.7 \%$ & $37.7 \%$ \\
\hline & Daily leader has a formalized managerial education & $35.8 \%$ & $60.5 \%$ & $16.5 \%$ & $45.6 \%$ \\
\hline & Decision authority (dentist) & $87.4 \%$ & $31.3 \%$ & $81.1 \%$ & $45.8 \%$ \\
\hline \multirow{5}{*}{ 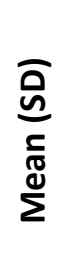 } & Weekly number of work hours with patients & $31.1(6.8)$ & $29.3(8.2)$ & $31.0(6.0)$ & $24.5(8.7)$ \\
\hline & Years since graduation & $26.0(10.0)$ & $21.4(12.2)$ & $25.9(8.9)$ & $23.8(8.3)$ \\
\hline & Network (range 0-100) & $60(14)$ & $54(13)$ & $62(14)$ & $61(14)$ \\
\hline & Professional climate (range 0-100) & $78(14)$ & $64(15)$ & $72(14)$ & $72(14)$ \\
\hline & Productivity climate (range $0-100$ ) & $70(17)$ & $68(18)$ & $66(16)$ & $60(15)$ \\
\hline
\end{tabular}


Table III. Multiple linear hierarchical block regression with Collegial Support as dependent variable (range 0-100). Significant values marked in bold face.

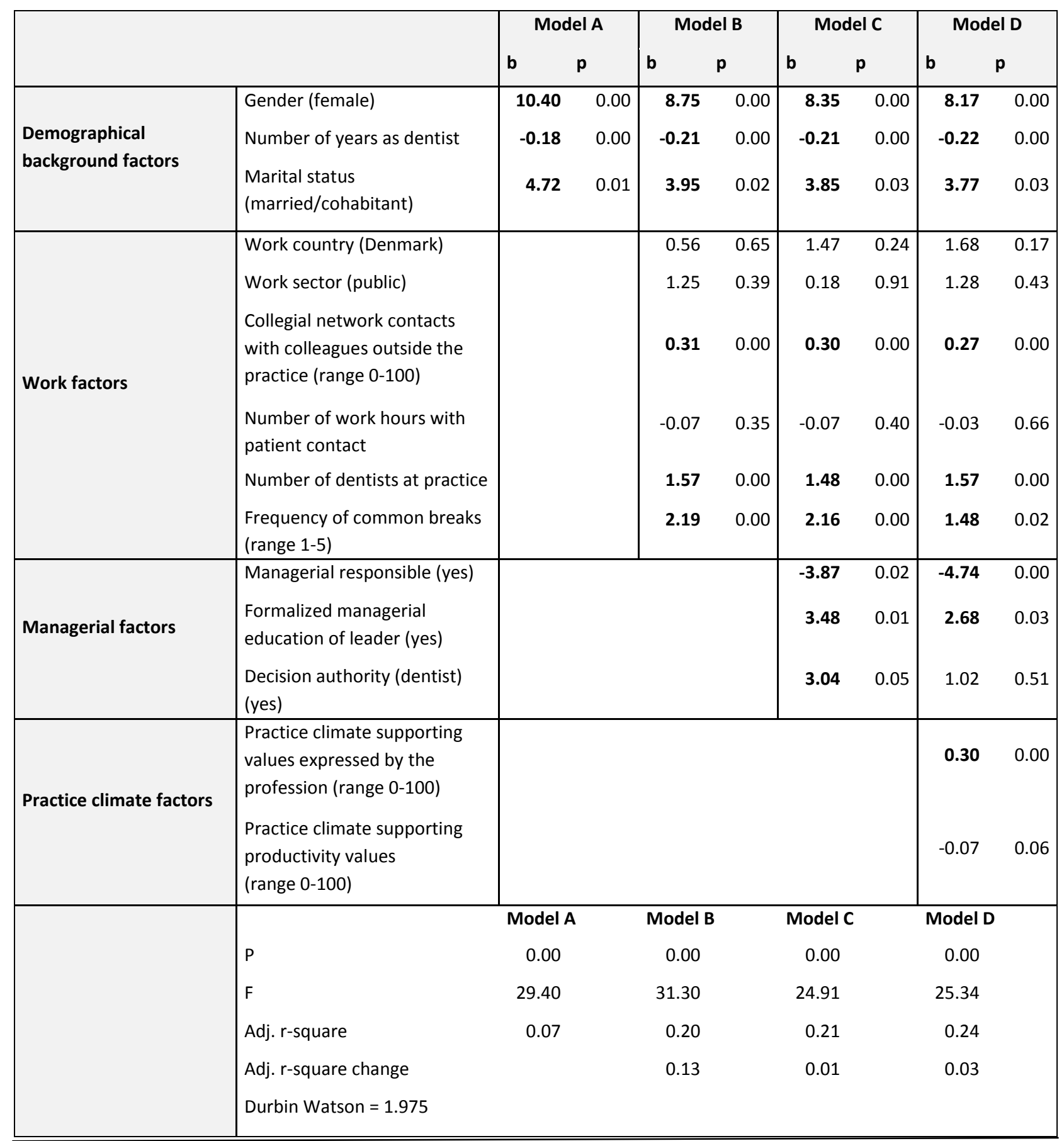


Table IV. Multiple linear hierarchical block regression with Community with Trust as dependent variable (range 0-100). Significant values marked in bold face.

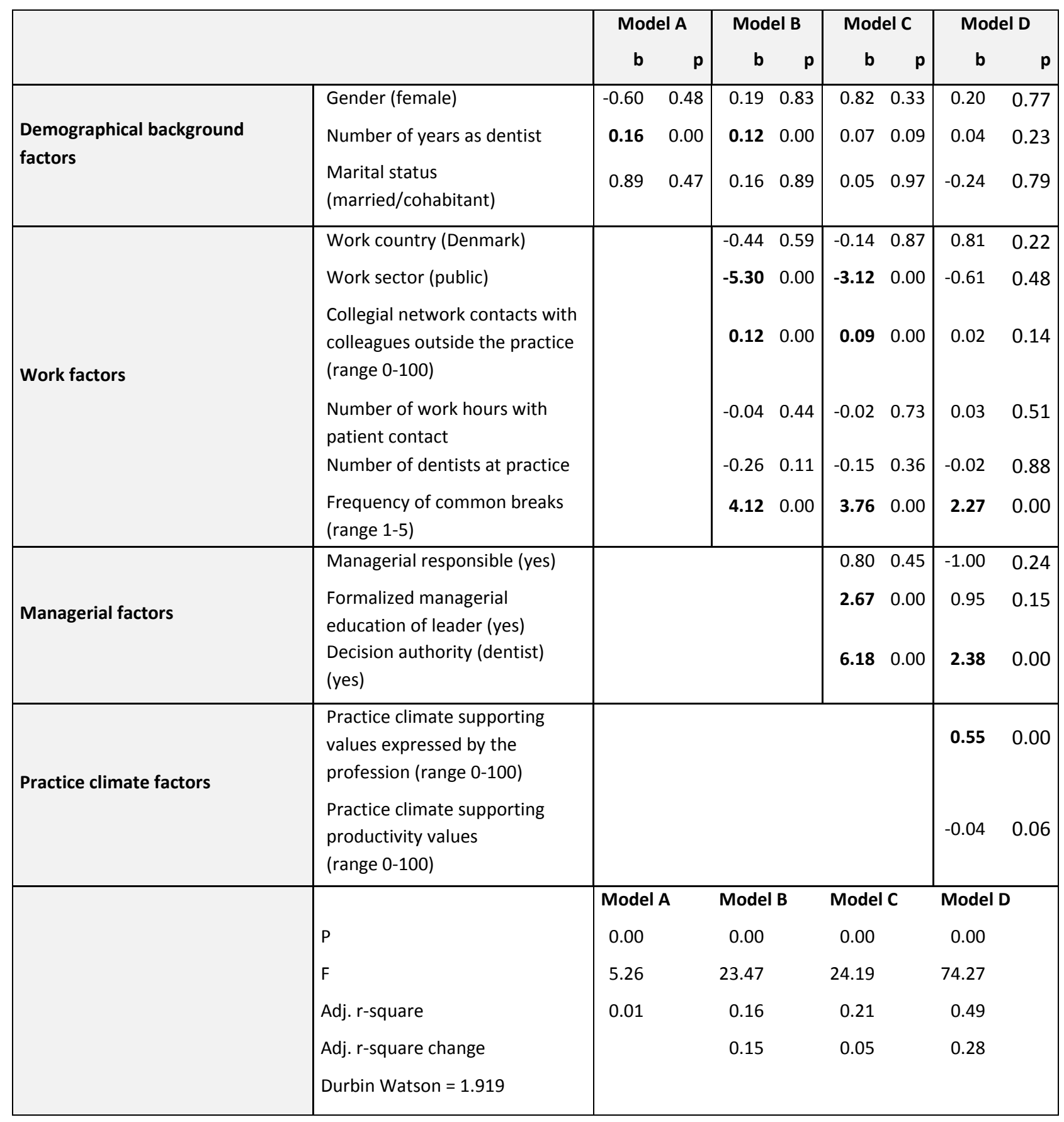


Table V. Overview of hypotheses and results.

+ indicate a positive relationship, -a negative relationship, and 0 that the hypothesis is rejected.

\begin{tabular}{|c|c|c|c|c|}
\hline & Hypothe & ses & Results & \\
\hline & $\begin{array}{l}\text { Community } \\
\text { with Trust }\end{array}$ & $\begin{array}{l}\text { Collegial } \\
\text { Support }\end{array}$ & $\begin{array}{l}\text { Community } \\
\text { with Trust }\end{array}$ & $\begin{array}{l}\text { Collegial } \\
\text { Support }\end{array}$ \\
\hline 1. Number of dentists at practice & + & + & 0 & + \\
\hline 2. Frequency of common breaks & + & + & + & + \\
\hline $\begin{array}{l}\text { 3. Formalized managerial education } \\
\text { of leader }\end{array}$ & + & + & 0 & + \\
\hline 4. Decision authority (influence) & + & + & + & 0 \\
\hline 5. Professional climate & + & + & + & + \\
\hline 6. Productivity climate & - & - & 0 & 0 \\
\hline
\end{tabular}

